\title{
Effect of Heat Treatment on the Mechanical Properties of Squeeze-Cast Al-5Si-3Cu Alloy for Automotive Applications
}

\author{
M. G. Akhil ${ }^{1} \cdot$ S. Preenu ${ }^{2} \cdot$ S. Hari ${ }^{1} \cdot$ M. Ravi ${ }^{1}$
}

Received: 2 September 2018/ Accepted: 3 January 2019/Published online: 28 March 2019

(C) The Author(s) 2019

\begin{abstract}
Al}-\mathrm{Si}-\mathrm{Cu}$ alloy (A319) castings are used in vehicle industry due to its better castability, high specific strength, corrosion resistance and low cost. Using this alloy, most of the automotive components are manufactured by gravity die casting or high-pressure die casting technique, but these castings contain higher porosity leading to rejections. Squeeze casting is an emerging casting technique in which solidification is done under high pressure which overcomes the drawbacks of the gravity and pressure die casting. It offers higher metal yield, minimum porosity and near-net-shaped products with enhanced mechanical properties. Typical $\mathrm{Al}-\mathrm{Si}-\mathrm{Cu}$ cast alloys are heat-treated for $\mathrm{T} 6$ condition for attaining tensile strength in the range of 250-300 MPa and elongation up to 3\%. The mechanical properties of this alloy can be further improved by the addition of $\mathrm{Mg}$ and $\mathrm{Sr}$ modification and by subjecting to squeeze casting. The present study deals with the optimization of the heat treatment cycle of squeeze-cast alloy billets and compares squeeze-cast alloy with the gravity-cast alloy in terms of mechanical properties and wear behaviour.
\end{abstract}

M. Ravi

manickravi@yahoo.com

M. G. Akhil

akhilmg117@gmail.com

S. Preenu

preenusreedhar7314@gmail.com

S. Hari

harisanil1508@gmail.com

1 CSIR-National Institute for Interdisciplinary Science and Technology, Trivandrum, Kerala 695019, India

2 Sree Chitra Thirunal College of Engineering, Trivandrum, Kerala 695018, India
Keywords A319 alloy - Sr modification . Squeeze casting $\cdot$ T6 heat treatment

\section{Introduction}

$\mathrm{Al}-\mathrm{Si}-\mathrm{Cu}$ (A319) alloy is widely used in the automotive industries due to their good castability, low thermal expansion coefficient and excellent mechanical properties due to the formation of $\mathrm{Al}_{2} \mathrm{Cu}$ precipitate during heat treatment [1]. The automotive components like suspension arms, engine blocks, etc., operate over a wide range of stress conditions which demands enhanced mechanical properties than the existing alloy. The literature indicates that the mechanical strength and wear properties of this alloy can be further enhanced by minor additions of $\mathrm{Mg}$ and $\mathrm{Sr}$ modification.

Squeeze casting (SC) is an advanced casting technique in which high pressure is employed during solidification of molten metal in the die cavity. Solidification under higher pressure eliminates gas and shrinkage porosities in the casting. Higher cooling rate caused by the improved thermal contact between the casting and the die results in the formation of fine grained microstructure. The squeeze casting technique is the most effective method of manufacturing complex near-net-shaped automobile components with high strength and desired elongation [2].

Mg addition to the existing A319 alloy improves the mechanical properties such as tensile strength and wear resistance due to the combined precipitation of $\mathrm{CuAl}_{2}$ and $\mathrm{Mg}_{2} \mathrm{Si}$ precipitates during heat treatment [3]. The morphology of eutectic silicon in A319 alloy also has a considerable influence on the mechanical properties of the casting. The eutectic silicon morphology can be controlled 
by the addition of strontium to the melt which results in a fine and fibrous silicon structure during solidification thereby improving the ductility, fracture toughness and wear resistance $[4,5]$.

\section{Experimental}

Commercial A319 alloy ingots were used in this study. The ingots were cleaned, preheated and melted in the electrical resistance pit furnace and allowed to attain temperature up to $750{ }^{\circ} \mathrm{C}$. The temperature of the melt was measured and monitored using $\mathrm{Cr}-\mathrm{Al}$ thermocouple. The melt was degassed for $1 \mathrm{~h}$ using dry nitrogen, which was bubbled through concentrated sulphuric acid and anhydrous calcium chloride. About 0.5 weight percentage of $\mathrm{Mg}$ was added to the melt in the form of $\mathrm{Al}-20 \mathrm{Mg}$ master alloy. For modification, 0.02 weight percentage of $\mathrm{Sr}$ (Al-10Sr master alloy) was then added to the melt during degassing. The molten metal was then poured at a temperature of $710-720{ }^{\circ} \mathrm{C}$ into the preheated metallic mould (in the case of gravity die casting) and into the preheated mould cavity of the die attached to the fixed base of the squeeze casting machine. A squeezing pressure of $100-120 \mathrm{~kg} / \mathrm{cm}^{2}$ was applied and the melt was allowed to solidify under pressure for 5-10 min. Table 1 shows the chemical composition of the standard A319 alloy ingot and the Mg- and Sr-added alloy used in the present study.

After solidification, the castings were removed from the die and cut into the required dimensions and machined for the microstructural analysis and heat treatment studies (for the evaluation of hardness, wear and tensile behaviour). Hardness measurements were taken using Tinius Olsen hardness testing machine. Wear rate of the alloys was measured using dry sliding-pin-on-disc wear testing machine according to ASTM G99-05 [ASM, 1992] standard. Tensile specimens were prepared as per ASTM standards E8M-04. The tensile specimens were tested in a universal testing machine (Instron 5500R) at a constant cross head speed of $1 \mathrm{~mm} / \mathrm{min}$. For each condition, a total of at least three samples were tested and the average value was reported.

\section{Heat Treatment}

In the present study, T6 heat treatment was carried out and the samples were subjected to solution treatment at a temperature of $500{ }^{\circ} \mathrm{C}$ for varying time followed by quenching in water. Solution heat treatment was performed for a definite duration to obtain a homogeneous structure, followed by quenching to attain supersaturated solid solution at ambient temperature. During solution treatment, the eutectic Si underwent necking and separated into segments. There was a decrease in the average particle size due to this fragmentation, and the fragmented segments were spheroidized. The ageing temperature of $170{ }^{\circ} \mathrm{C}$ was adopted in all the cases, and the duration of ageing was varied from 1 to $16 \mathrm{~h}$ to find the time required for peak hardening.

\section{Chemical Composition}

The analysis of chemical composition using optical emission spectrometer confirms that the alloying elements are within the specified limits.

\section{Results and Discussion}

The microstructure of the gravity- and squeeze-cast samples of the A319-0.5 Mg-0.02Sr alloy is shown in Fig. 1. From the microstructural observation, it is evident that the squeeze-cast sample is much finer compared to gravity-cast samples. The porosity is absent in the squeeze-cast samples. The unmodified gravity-cast 319 alloy consists of alternate layers of eutectic aluminium and acicular eutectic silicon in the inter-dendritic regions of $\alpha$-aluminium. The acicular eutectic silicon is believed to act as stress raisers in the microstructure making the material fail in a brittle mode [6, 7]. However, in the squeeze-cast alloy, finer microstructure is obtained with smaller and well-distributed eutectic silicon. On heat treatment, the morphology of eutectic silicon is changed from acicular to rounded ones and is significantly very fine in the case of squeezecast alloy.

The combined precipitation of $\mathrm{Al}_{2} \mathrm{Cu}$ and $\mathrm{Mg}_{2} \mathrm{Si}$ precipitates during ageing of 319-0.5 Mg alloy improves the strength properties. Finer microstructure caused by squeeze

Table 1 The chemical composition of $\mathrm{Al}-\mathrm{Si}-\mathrm{Cu}(\mathrm{Mg})$ alloy castings

\begin{tabular}{llllllll}
\hline Alloy code & $\mathrm{Si}$ & $\mathrm{Fe}$ & $\mathrm{Cu}$ & $\mathrm{Mg}$ & $\mathrm{Sr}$ & $\mathrm{Ti}$ \\
\hline A1 (wt\%) & 5.345 & 0.107 & 3.634 & $<0.0001$ & 0.017 & 0.053 \\
A2 (wt\%) & 5.395 & 0.201 & 3.589 & 0.457 & 0.018 & 0.049 & 89.65 \\
\hline
\end{tabular}


Fig. 1 Microstructure of A $319-0.5 \mathrm{Mg}-0.04 \mathrm{Sr}$, a gravity as-cast, b squeeze as-cast, c gravity heat-treated, $\mathbf{d}$ squeeze heat-treated

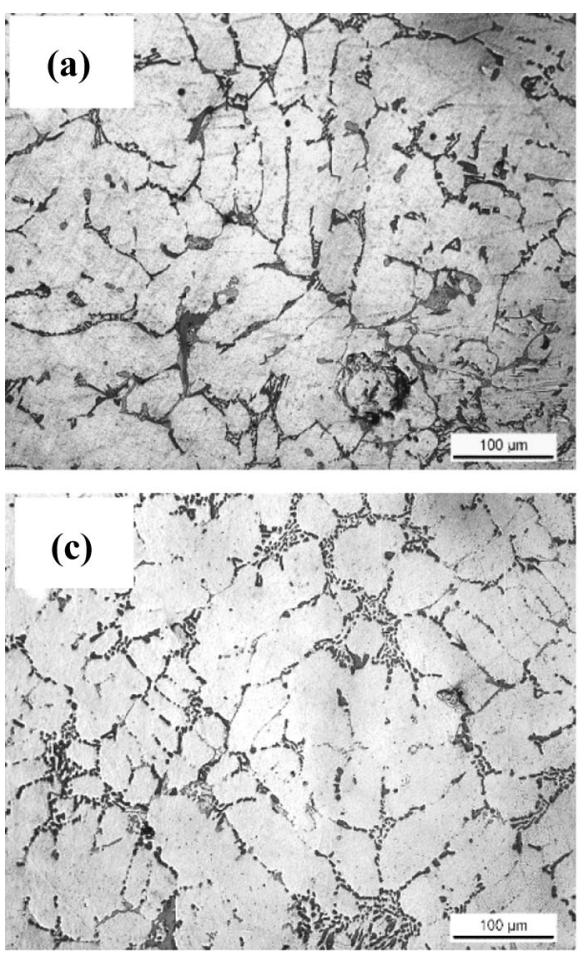

casting process and ageing treatment together contributes to the improved hardness and mechanical properties of the alloy. The addition of strontium results in a fine and fibrous eutectic silicon structure which contributes to the improved ductility of the alloy [8-10].

\section{Hardness and Wear Behaviour}

Figure 2 shows the variation in hardness values of gravitycast and squeeze-cast alloys under different ageing times. The maximum hardness value for squeeze-cast alloy under peak-aged condition is $110 \mathrm{BHN}$, whereas that for gravity-

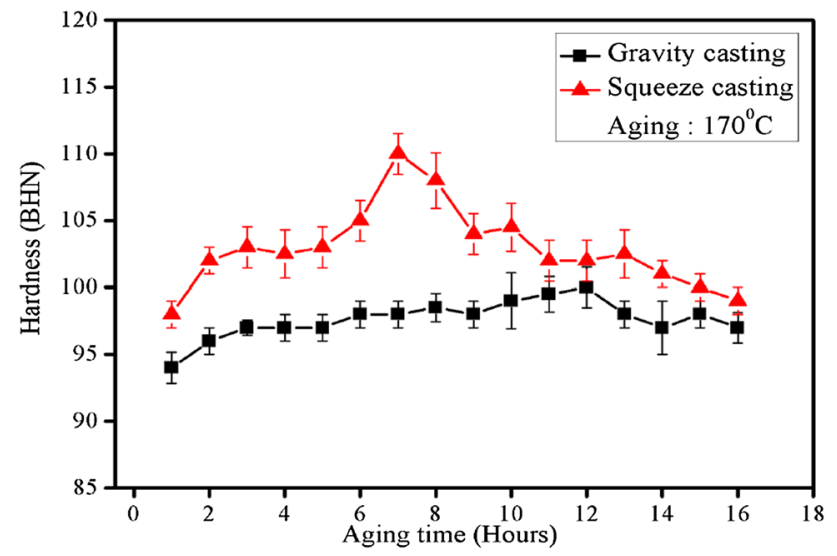

Fig. 2 Variation of hardness with ageing time cast alloy is $100 \mathrm{BHN}$. The peak values for hardness are obtained at $7 \mathrm{~h}$ and $12 \mathrm{~h}$ of ageing, respectively.

The wear rate is determined using pin-on-disc tester and calculated from the weight loss of wear samples of peakaged gravity- and squeeze-cast alloy under different loading conditions. Figure 3 shows the correlation between weight loss and load of heat-treated gravity- and squeezecast alloy samples. From the wear test analysis, it is observed that the heat-treated squeeze-cast alloys exhibit lower wear rate compared to the heat-treated gravity-cast alloy samples.

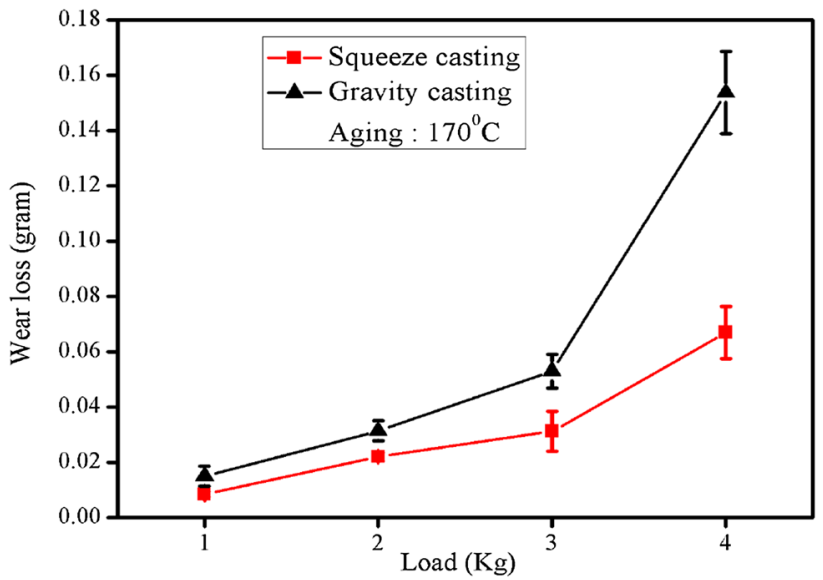

Fig. 3 Wear behaviour of gravity- and squeeze-cast alloys 

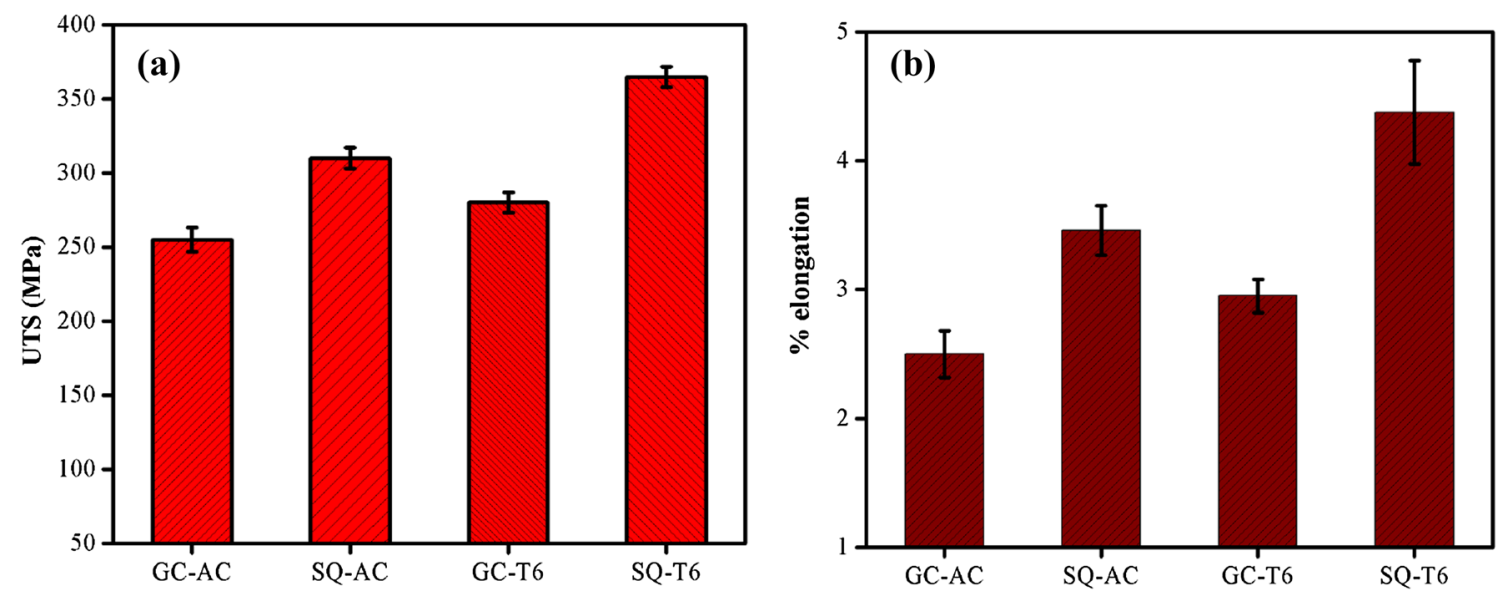

Fig. 4 a Ultimate tensile strength and $\mathbf{b} \%$ elongation of alloy A2 under gravity- and squeeze-cast conditions

\section{Tensile Properties}

Figure 4 shows the tensile results of gravity- and squeezecast alloy samples (alloy A2) which indicates higher mechanical properties of the squeeze-cast samples both in the as-cast condition and in the T6 condition. For each casting condition, four specimens have been tested and error values are reported.

\section{Conclusion}

The mechanical properties of the A319 alloy were enhanced by the addition of $\mathrm{Mg}, \mathrm{Sr}$ modification and squeeze casting. A finer microstructure was observed for the squeeze-cast samples which contributed to a significant improvement in the hardness, tensile and elongation under peak-aged condition. The peak hardness of $110 \mathrm{BHN}$ was attained for ageing for $7 \mathrm{~h}$ at $170{ }^{\circ} \mathrm{C}$ for squeeze-cast alloy samples compared to $12 \mathrm{~h}$ for the gravity-cast samples. A lower wear rate was observed for the peak-aged squeezecast alloy samples. The higher mechanical properties of the squeeze-cast alloy fulfiled the strength requirements of automotive components.

Acknowledgements The authors would like to thank the Director, CSIR-NIIST, Trivandrum, for granting permission to publish this paper. The authors thank the members of Material Science and Technology Division, for their technical support for the present work.
Open Access This article is distributed under the terms of the Creative Commons Attribution 4.0 International License ( http://creativecommons.org/licenses/by/4.0/), which permits unrestricted use, distribution, and reproduction in any medium, provided you give appropriate credit to the original author(s) and the source, provide a link to the Creative Commons license, and indicate if changes were made.

\section{References}

1. Ghomashchi M R, and Vikhrov A, J Mater Process Technol 101 (2000), 1.

2. Zhang M, Zhang W, Zhao H, Zhang D, and Li Y, Trans Nonferrous Met Soc China 17 (2007) 496.

3. Weakley-Bollin S C, Donlon W, Wolverton C, Allison J E, and Jones J W, Metall Mater Trans A 35 (2004) 2407.

4. Tavitas-Medrano F J, Gruzleski J E, Samuel F H, Valtierra S, and Doty H W, Mater Sci Eng A 480 (2008) 356.

5. Alhawari K S, Omar M Z, Ghazali M J, Salleh M S, and Mohammed M N, Mater Des 76 (2015) 169.

6. Dahle A K, Nogita K, McDonald S D, Dinnis C, and Lu L, Mater Sci Eng A 413 (2005) 243.

7. Pasko J, and Gaspar S, in Advanced Materials Research, Trans Tech Publications 1014 (2014), p 9.

8. Fatahalla N, Hafiz M, and Abdulkhalek M, J Mater Sci 34 (1999) 3555.

9. Shin S S, Kim E S, Yeom G Y and Lee J C, Mater Sci Eng A 532 (2012) 151

10. Sui Y, Wang Q, Wang G and Liu T J Alloys Compd 622 (2015) 572.

Publisher's Note Springer Nature remains neutral with regard to jurisdictional claims in published maps and institutional affiliations. 